\title{
Temporal stability of electrical conductivity in a sandy soil**
}

\author{
Aura Pedrera-Parrilla ${ }^{1}$, Eric C. Brevik ${ }^{2}$, Juan V. Giráldez ${ }^{3,4}$, and Karl Vanderlinden ${ }^{1}$ \\ ${ }^{1}$ IFAPA, Las Torres-Tomejil Center, Sevilla-Cazalla km 12.2, 41200 Alcalá del Río, Sevilla, Spain \\ ${ }^{2}$ Department of Natural Sciences, 291 Campus Drive, Dickinson State University, Dickinson ND 58601, USA \\ ${ }^{3}$ Department of Agronomy, University of Cordoba, Rabanales Campus, Building L. da Vinci, Madrid Road km 396, \\ 14071 Córdoba, Spain \\ ${ }^{4}$ Institute for Sustainable Agriculture, CSIC, Avda, Menéndez Pidal s/n, 14080 Córdoba, Spain
}

Received January 25, 2016; accepted June 10, 2016

A b s t r a c t. Understanding of soil spatial variability is needed to delimit areas for precision agriculture. Electromagnetic induction sensors which measure the soil apparent electrical conductivity reflect soil spatial variability. The objectives of this work were to see if a temporally stable component could be found in electrical conductivity, and to see if temporal stability information acquired from several electrical conductivity surveys could be used to better interpret the results of concurrent surveys of electrical conductivity and soil water content. The experimental work was performed in a commercial rainfed olive grove of 6.7 ha in the 'La Manga' catchment in SW Spain. Several soil surveys provided gravimetric soil water content and electrical conductivity data. Soil electrical conductivity values were used to spatially delimit three areas in the grove, based on the first principal component, which represented the time-stable dominant spatial electrical conductivity pattern and explained $86 \%$ of the total electrical conductivity variance. Significant differences in clay, stone and soil water contents were detected between the three areas. Relationships between electrical conductivity and soil water content were modelled with an exponential model. Parameters from the model showed a strong effect of the first principal component on the relationship between soil water content and electrical conductivity. Overall temporal stability of electrical conductivity reflects soil properties and manifests itself in spatial patterns of soil water content.

K e y w o r d s: apparent electrical conductivity, soil texture, soil water content, spatial variability, temporal stability

*Corresponding author e-mail: aura.pedrera@hotmail.com

**Funding for this work came from the Spanish Ministry of Economy and Competitiveness and FEDER (Grants AGL201240128-C03-03 and AGL2015-65036-C3-3-R, MINECO/FEDER, UE)), and from the Junta de Andalucía (P11-AGR-7431). Also support through Ph.D. grant No. 8 (Res. 15/04/2010) by IFAPA is acknowledged).

\section{INTRODUCTION}

Soils are inherently variable in space and time (Brevik et al., 2016). Knowing this variability helps to establish proper soil and crop management and to ensure better use of available resources. Recent developments in sensing have led to an increase in surveys of spatial density of soil, and therefore better information regarding soil spatial and temporal variability (Doolittle and Brevik, 2014).

Measurements of apparent electrical conductivity $(E C a)$ provide high spatial data density and allow mapping in great detail. The $E C a$ values reflect various soil properties such as water content, salinity and/or sodicity, clay content, organic matter content, depth to contrasting soil layers, soil compaction, and organic carbon content (Heilig et al., 2011; Martinez et al., 2009; Saey et al., 2008).

Generally speaking, the more $E C a$ surveys that are carried out in a given area the more information that is collected about the spatial variation of soil properties. Several approaches have been proposed to make information from several surveys usable for management decisions. Martinez et al. (2012) combined multiple electromagnetic induction (EMI) sensor surveys to include more information coming from the $E C a$ variability using multiple regression analysis between the principal components of $E C a$ and soil water content (SWC). Sudduth et al. (2003) claim that although temporal variability exists in soil $E C a$, the relative pattern of soil $E C a$ distribution within a field is relatively stable.

(C) 2016 Institute of Agrophysics, Polish Academy of Sciences 
Under this assumption, Hedley et al. (2009) delimited three management zones based on a high resolution $E C a$ survey. Peralta et al. (2013), Pedrera-Parrilla et al. (2014), and Bonfante et al. (2015) have also used EMI to establish management zones. The delineation of management zones within a given field is one of the most common uses of EMI data (Vaudour et al., 2015).

Information from several surveys is also of importance to check whether a variable shows a stable temporal pattern. Temporal stability in $E C a$ data has been demonstrated using Spearman rank correlation (De Caires et al., 2015), correlation coefficient between $E C a$ in dry and wet soil conditions (Farahani et al., 2004; Pedrera-Parrilla et al., 2016; Serrano et al., 2013), and map comparisons (Li et al., 2007). One effective method of studying temporal stability of spatially and temporally variable soil properties consists in using principal component analysis (PCA) (Vanderlinden et al., 2012). PCA works by determining principal components (also called empirical orthogonal functions, EOFs) that are dependent only on spatial variables and can be added with temporally dependent coefficients to reproduce the original spatio-temporal data. In cases of well expressed temporal stability, a few principal components explain most of the data variability. Perry and Niemann (2007) used PCs to demonstrate temporal stability in the Tarrawarra soil moisture data set (Australia), and to reconstruct observed soil moisture patterns. Korres et al. (2010) found PCs in spatiotemporal data on surface soil moisture in CambisolStagnosol soils in Germany, where PC patterns were significantly correlated with patterns in soil properties. We are not aware of any applications of PCA to spatio-temporal datasets on soil $E C a$.

The first objective of this work was to apply PCA to check whether a temporally stable component could be found for $E C a$ in sandy soils in a Mediterranean watershed, where soils are very dry for substantial periods of time during the year. The second objective was to determine if temporal stability information acquired from several $E C a$ surveys could be used to better interpret results from a single survey in terms of relationships between $E C a$ and soil water content.

\section{MATERIAL AND METHODS}

The experimental catchment, 'La Manga' ( $36^{\circ} 52^{\prime}$ ' 21 '" $\mathrm{N}, 5^{\circ} 7^{\prime} 44^{\prime \prime} \mathrm{W}$ ), is located in Setenil de las Bodegas, SW Spain, and covers 6.7 ha of a rainfed olive grove. The trees were planted in 1995 on a $7 \times 7 \mathrm{~m}$ grid, with an average tree density of about 200 trees ha-1. The mean elevation is $740 \mathrm{~m}$ a.s.l. and the landscape is hilly with a mean slope near $10 \%$ (Fig. 1). The soil subgroup is an intergrade between Lithic and Typic Rhodoxeralfs (García del Barrio et al., 1971; Soil Survey Staff, 1999), with a loamy sand texture and a maximum depth of $1.2 \mathrm{~m}$ to the calcarenite bedrock. In areas with weakly developed soils, such as the Setenil region, the

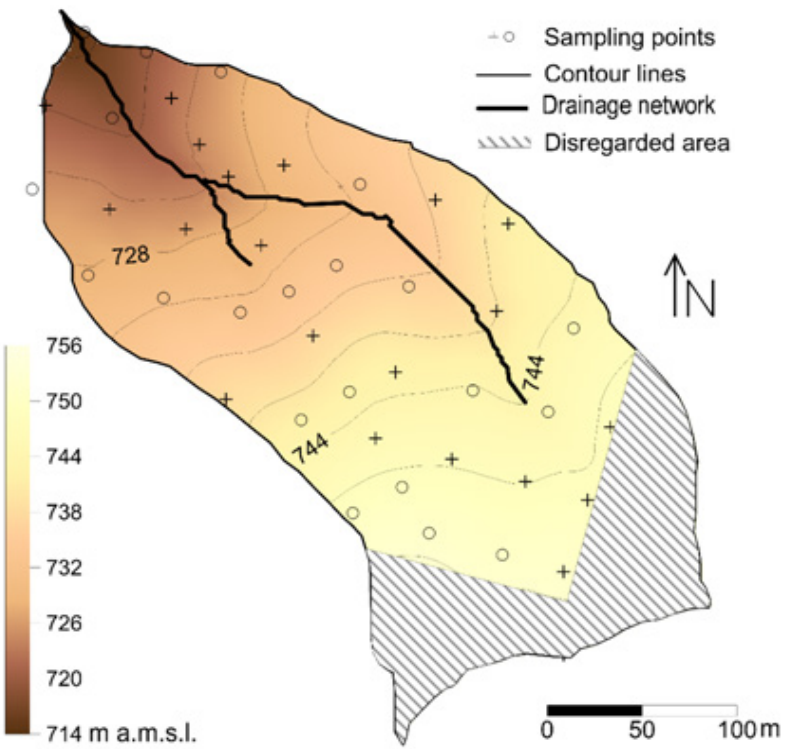

Fig. 1. Topographical characterisation of the catchment: Contour lines, drainage network and location of soil sampling points. Circles indicate where the bulk density $\left(\rho_{b}\right)$ samples were taken and the hatched area at the bottom of the figure corresponds to an area of the catchment that was not included in this study because it is under different management.

rugged relief often leads to partial loss of the topsoil layer (Ibañez et al., 2015; Symeonakis et al., 2014). This is a natural process aggravated by certain agricultural practices $(\mathrm{eg}$ tillage) (Gómez et al., 2009; Keesstra et al., 2016; Taguas and Gómez, 2015; Vanwalleghem et al., 2011), leading to outcropping of the bedrock and to the appearance of localised zones where the humus-rich horizon rarely exceeds $0.1 \mathrm{~m}$. The climate is Mediterranean, with a mean annual precipitation of $700 \mathrm{~mm}$, where $75 \%$ of the rainfall occurs from October to May. The grove is under minimum tillage and weeds are controlled with chemical herbicides. The field was tilled in January 2011 and in March 2012. A gully draining the catchment from the SE towards the catchment outlet in the NW separates the two main subareas with different slopes and aspects.

Soil profile samples were collected in March 2011 at 41 locations on a pseudo-regular grid (Fig. 1), using a $0.093 \mathrm{~m}$ diameter steel cylinder with a percussion drill. Soil samples were taken at intervals of $0.1 \mathrm{~m}$ from the surface down to $1.2 \mathrm{~m}$, where possible. The samples were analysed in the laboratory for soil texture, stone content and bulk density $\left(\rho_{b}\right)$. As a result of the shallow soil depth, samples were only available for the first two and three depth intervals at 90 and $52 \%$ of the locations, respectively. In order to obtain a spatially consistent soil data set for a homogeneous depth interval, the corresponding values of the first two intervals $(0-0.2 \mathrm{~m})$ were averaged. Texture was determined with the hydrometer method (Gee and Or, 2002), stone content by conventional methods (Grossman and Reinsch, 2002), and $\rho_{b}$ using the core method (Blake and Hartge, 1986) from 
undisturbed samples taken with $250 \mathrm{~cm}^{3}$ stainless steel rings at 21 locations, evenly distributed over the catchment, at depths of 0.05 and $0.15 \mathrm{~m}$, and averaged to obtain $\rho_{b}$ for the $0-0.2 \mathrm{~m}$ interval. The catchment was sampled on 18 occasions for gravimetric $S W C$ (Fig. 2) at the 0-0.1 and 0.1-0.2 m depth intervals, at the same 41 locations, during two hydrological years (February 2011 - November 2012), using a $0.05 \mathrm{~m}$ diameter Edelman auger, and the corresponding values of the first two intervals $(0-0.2 \mathrm{~m})$ were averaged.

At the same 41 locations where soil properties were characterised, $E C a$ was measured on nine occasions (surveys $9,10,11,12,14,15,16,17$ and 18) using a DUALEM21S EMI sensor (DUALEM, Milton, Canada). In addition, seven field-wide $E C a$ surveys were conducted (surveys $10,12,13,15,16,17$ and 18). All the available $E C a$ data were included in the analyses. The DUALEM-21S works at a frequency of $9 \mathrm{kHz}$ and is composed of four receiver coils located at distances of 1, 1.1,2 and $2.1 \mathrm{~m}$ from the transmitter coil and arranged in horizontal-coplanar $(\mathrm{H})$ and perpendicular (P) configurations (Dualem Inc. 2007), allowing simultaneous ECa measurements of four different soil volumes with different depths of exploration (DOE). DOE is defined as the depth at which $70 \%$ of the $E C a$ response is obtained from the soil volume above that depth (McNeill, 1980; Callegary et al., 2007). These values are approximately $1.5,0.5,3$ and $1 \mathrm{~m}$, respectively, for the above mentioned receiver coils.

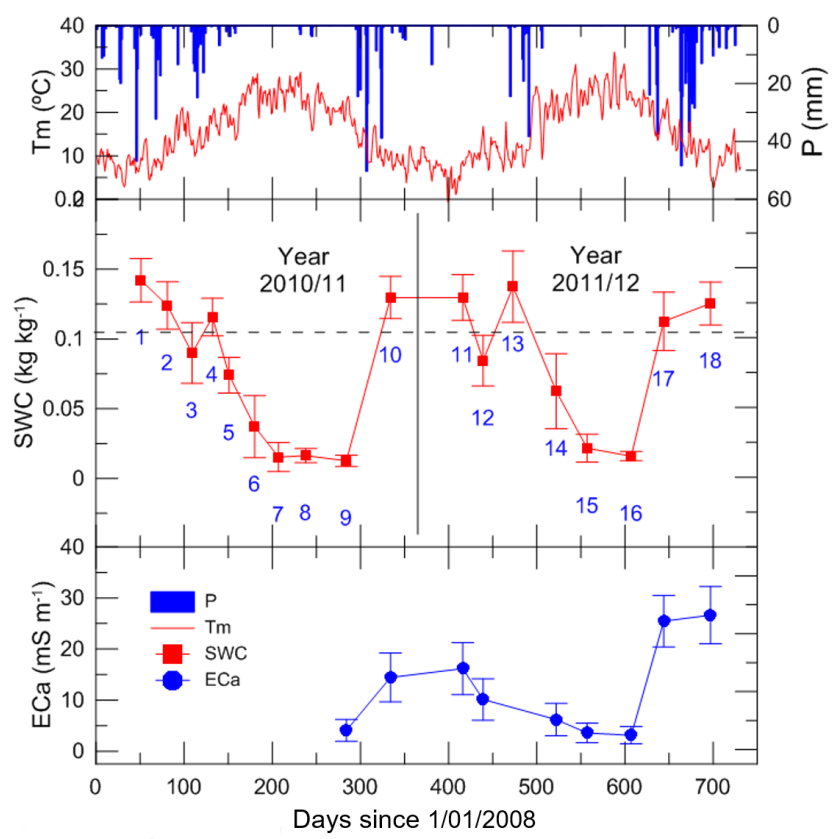

Fig. 2. Temporal evolution of temperature $\left(T, C^{o}\right)$, precipitation $(\mathrm{P}, \mathrm{mm})$, mean soil water content $\left(S W C, \mathrm{~kg} \mathrm{~kg}^{-1}\right)$ and mean apparent electrical conductivity $\left(E C a, \mathrm{mS} \mathrm{m}^{-1}\right)$ for hydrological years 2011 and 2012. Error bars represent standard deviations. Dashed line shows the threshold for what we considered to be high SWCs in this field.
The EMI soil sensor was placed in a non-metallic sled and pulled by an all-terrain vehicle (ATV) at a speed of $5-10 \mathrm{~km} \mathrm{~h}^{-1}$. The DUALEM-21S was positioned inside the sled at a height of $0.075 \mathrm{~m}$ above the soil surface as a result of a wear-and-tear plate made of PVC which was mounted underneath the sled to protect it from abrasion by dry soil and stones. The ATV was equipped with a real time kinematic-differential GPS receiver (Trimble, Sunnyvale, CA) and a rugged Allegro-TK6000 field computer (Juniper Systems, Logan, UT) to simultaneously $\log E C a$ measurements, coordinates and terrain elevation once per second.

The average soil temperature, measured by a $5 \mathrm{TE}$ (Decagon Devices, Pullman, WA) sensor network (Espejo et al., 2014), was used to standardise the $E C a$ values to a reference temperature of $25^{\circ} \mathrm{C}$ (Sheets and Hendrickx, 1995). Because slightly negative $E C a$ values were recorded in some instances, due to the low values measured and their narrow range in this field, $E C a$ data were referenced to zero, after temperature correction, by subtracting the minimum $E C a$ value from every $E C a$ value. GPS coordinates were registered in WGS84 and transformed to the UTM projection ETRS89 datum $30 \mathrm{~N}$, with the software Utm9e-200803 (Núñez-Maderal, 2008). The $E C a$ data were filtered to remove possible outliers using the approach proposed by Simpson (2009), and interpolated using ordinary point kriging (Goovaerts, 1997) to create maps for the $E C a$ signal with a DOE of approximately $1.5 \mathrm{~m}$. The interpolated maps $(1 \times 1 \mathrm{~m})$ for the $7 E C a$ catchment-wide surveys were computed using the Vesper software package (Whelan et al., 2002). All the variables were interpolated using ordinary kriging.

The spatial representativeness of each individual $E C a$ map was characterised by quartiles. First (Q1) and third (Q3) quartiles were calculated in order to delineate three zones (Z1, Z2 and Z3) in the field and to group the 41 sampling locations according to this classification: $Z 1$, locations with $E C a<\mathrm{Q} 1 ; \mathrm{Z} 2$, locations with $E C a>\mathrm{Q} 3$; and $\mathrm{Z} 3$, locations with $E C a$ outside the data range for $\mathrm{Z1}$ and Z2. Therefore, for each individual $E C a$ map the field was classified based on quartiles (Z1, Z2 and Z3). An analysis of variance (ANOVA) was performed to check whether differences in measured soil data among the different zones were significant. Next a PCA was performed using Matlab (version R2009b, The Mathworks Inc., USA). This transformation consists of inferring independent linear combinations of the analysed variables (here $E C a$ measured on different dates) which are called principle components (PC). The first PC explains the largest proportion of the total variance in the data and represents, in this case, the dominant spatial ECa pattern (Malinowski, 1991). A PCA for the $7 E C a$ maps was calculated to obtain the dominant spatial pattern of $E C a$. Based on the spatial distribution of the first $\mathrm{PC}$, the 41 sampling locations were then grouped into three new classes $(\mathrm{C} 1, \mathrm{C} 2$ and $\mathrm{C} 3)$ based on the first PC 


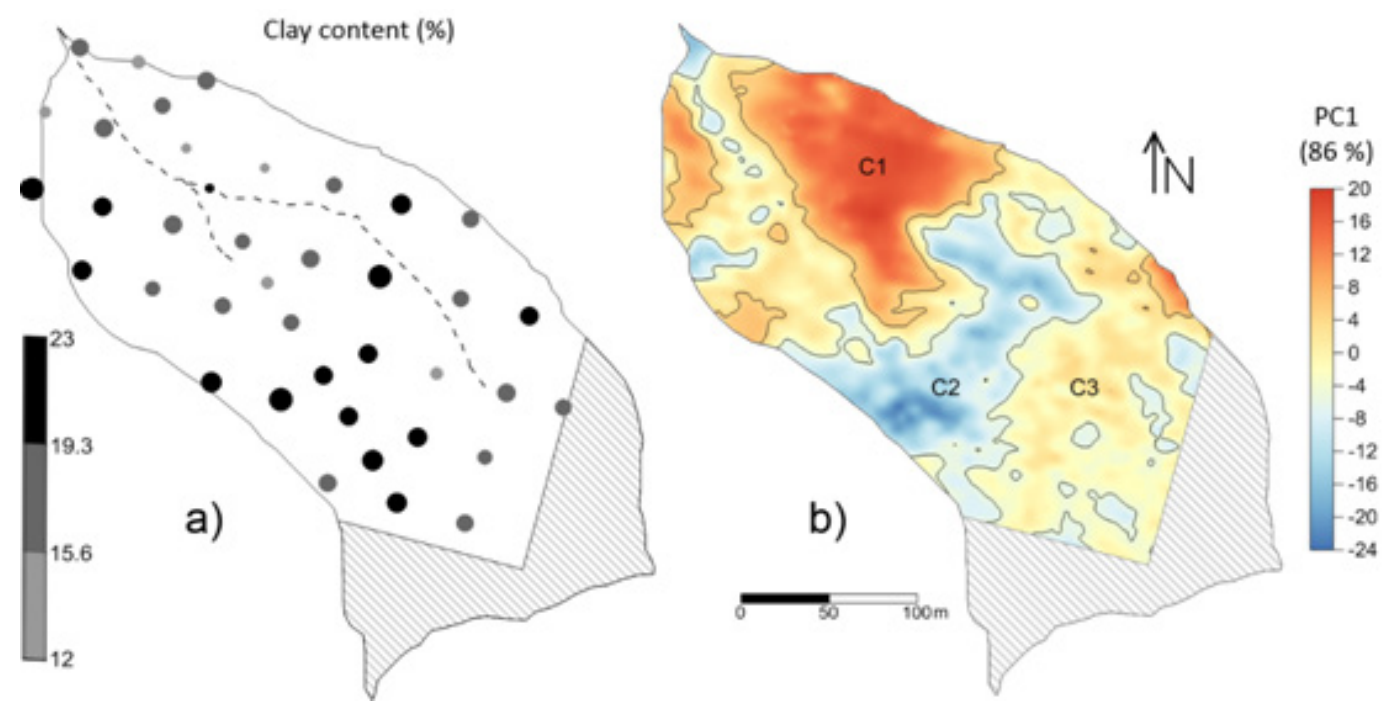

Fig. 3. a) Location map for clay content (\%). The diameter of the circles is proportional to the values, and b) map of the first principal component (PC1) overlying the limits of clases $\mathrm{C} 1, \mathrm{C} 2$ and $\mathrm{C} 3$. The hatched area at the bottom of the figure corresponds to the area of the catchment not included in this study.

quartiles. After that the stability of the quartile based classification was evaluated. The spatial classifications obtained from individual $E C a$ maps were compared with the spatial classification based on the first PC.

An exponential model was fitted to the relationship between the nine $E C a$ and $S W C$ surveys for each sampling location $i$ :

$$
E C a_{i}=a \exp \left(b S W C_{i}\right),
$$

where: $a$ and $b$ are fitting parameters, the subindex $i(i=1$, $2,3 \ldots 41)$ represents the soil sampling location, $S W C$ is the soil water content in $\mathrm{kg} \mathrm{kg}^{-1}$ and $E C a$ is the apparent electrical conductivity in $\mathrm{mS} \mathrm{m}^{-1}$. To quantify the precision of the fit, the coefficient of determination $\left(\mathrm{R}^{2}\right)$ and the root mean squared error (RMSE) between measured $\left(E C a_{m}\right)$ and estimated $\left(E C a_{e}\right)$ values were used.

The values of the fitting parameters were checked for significant differences between the three classified areas (C1, C2 and C3) and related to the first PC in order to fit a simple model to interpret the $S W C$ distribution through the time-stable dominant spatial $E C a$ pattern.

\section{RESULTS}

Soil texture at the site was dominated by a high and spatially uniform $(C V=5 \%)$ sand content. Averaged values for clay and stone content were 18 and $7 \%$, with a standard deviation of 2.5 and $6 \%$, respectively. The average $\rho_{b}$ value was $1.76 \mathrm{Mg} \mathrm{m}^{-3}$, and standard deviation for the field was $0.10 \mathrm{Mg} \mathrm{m}^{-3} ; \rho_{b}$ variations of this level are unlikely to significantly influence the $E C a$ readings (Brevik and Fenton, 2004). Stone content showed great spatial variability across the catchment, with higher stone contents occurring mainly on the south facing slopes, in the northern part of the catchment (Fig. 1). The spatial distribution of averaged clay content is given as a location map (Fig. 3a). The lowest clay content was found in the $\mathrm{N}$ part of the catchment, while in the SE part an area with higher clay content can be seen, as well as in a N-S fringe in the central part of the catchment. In the south facing area, the combined occurrence of the highest stone and the lowest clay contents is indicative of the great intensity of soil erosive processes in this area (Fig. 1).

Point measurements generated distinctly different ranges of $S W C$ s during dry and wet periods (Fig. 2). Mean topsoil $S W C$ s near or below $0.02 \mathrm{~kg} \mathrm{~kg}^{-1}$ were commonly found during summer (surveys 9,15 and 16) and were overall associated with the highest $C V$, ranging from 31 to $50 \%$. Mean $S W C$ s over $0.11 \mathrm{~kg} \mathrm{~kg}^{-1}$ were observed during wet periods (surveys 10,11,13,17 and 18) and corresponded with the smallest $C V \mathrm{~s}$, ranging from 11 to $19 \%$. Surveys 12 and 14 showed intermediate mean $S W C$ values and $C V \mathrm{~s}$.

Descriptive statistics of the nine $E C a$ surveys revealed that surveys 17 and 18 had the highest mean ECa (Fig. 2) and the lowest $C V(20 \%)$. An intermediate mean $E C a$ and $C V$ was found for surveys 10,11 and 12 , while surveys 9 , 14,15 and 16 presented the lowest mean $E C a$ and the highest $C V(50 \%)$, corresponding to dry soil conditions. The relationships between $E C a$ and $S W C$ data for each sampling location showed strong and statistically significant $(\mathrm{p}<0.005)$ correlations, with $\mathrm{R}^{2}$ values ranging from 0.45 to 0.94 and a maximum RMSE of 11.5.

Descriptive statistics for the seven ECa maps also showed that surveys 17 and 18 had the highest mean ECa and the lowest $C V$, surveys 10,12 and 13 had an intermediate mean $E C a$ and $C V$, while surveys 15 and 16 presented the lowest mean $E C a$, corresponding to dry soil conditions. Results from the spatial representativeness analysis of each individual ECa map (Table 1) indicated 
T a b l e 1. Mean and standard deviation for clay and stone contents (\%) and soil water content $\left(S W C, \mathrm{~kg} \mathrm{~kg}^{-1}\right)$ for the delimited zones $(\mathrm{Z} 1, \mathrm{Z} 2$ and $\mathrm{Z3})$

\begin{tabular}{|c|c|c|c|c|c|c|c|c|}
\hline \multirow{2}{*}{\multicolumn{2}{|c|}{$\begin{array}{l}\text { Soil } \\
\text { property }\end{array}$}} & \multicolumn{7}{|c|}{ Survey } \\
\hline & & 10 & 12 & 13 & 15 & 16 & 17 & 18 \\
\hline \multirow[t]{3}{*}{ Clay } & $\mathrm{Z} 1$ & $15.54 \pm 2.38(b)$ & $15.54 \pm 2.38(b)$ & $15.54 \pm 2.38(\mathrm{c})$ & $15.54 \pm 2.38(b)$ & $16.45 \pm 2.45(b)$ & $15.56 \pm 1.98(b)$ & $15.75 \pm 2.34(b)$ \\
\hline & $\mathrm{Z} 2$ & $19.50 \pm 1.96(a)$ & $19.66 \pm 2.11(\mathrm{a})$ & $19.85 \pm 1.75(b)$ & $19.85 \pm 1.75(\mathrm{ab})$ & $19.20 \pm 2.41(\mathrm{ab})$ & $19.79 \pm 1.70$ (a) & $19.14 \pm 1.57(\mathrm{a})$ \\
\hline & $\mathrm{Z3}$ & $17.76 \pm 1.80$ (a) & $17.84 \pm 1.97(a)$ & $17.82 \pm 1.84(\mathrm{a})$ & $17.82 \pm 1.85(\mathrm{a})$ & $17.84 \pm 2.03(\mathrm{a})$ & $18.15 \pm 1.80(\mathrm{a})$ & $18.25 \pm 2.28(\mathrm{a})$ \\
\hline \multirow[t]{3}{*}{ Stone } & $\mathrm{Z1}$ & $10.34 \pm 6.23(\mathrm{a})$ & $10.34 \pm 6.23(\mathrm{a})$ & $10.34 \pm 6.23(\mathrm{a})$ & $10.00 \pm 5.63(\mathrm{a})$ & $9.43 \pm 5.93(a)$ & $9.57 \pm 5.88(a)$ & $10.75 \pm 6.01(a)$ \\
\hline & $\mathrm{Z} 2$ & $4.69 \pm 5.59(\mathrm{a})$ & $3.61 \pm 4.65(\mathrm{ab})$ & $4.48 \pm 5.77(\mathrm{a})$ & $3.48 \pm 4.17(\mathrm{ab})$ & $7.16 \pm 7.01(\mathrm{a})$ & $5.28 \pm 5.83(\mathrm{a})$ & $4.74 \pm 6.29$ (a) \\
\hline & $\mathrm{Z3}$ & $8.01 \pm 6.17(\mathrm{a})$ & $8.34 \pm 6.22(b)$ & $7.62 \pm 6.05(a)$ & $8.14 \pm 6.72(b)$ & $6.19 \pm 5.86(\mathrm{a})$ & $7.28 \pm 6.57(a)$ & $7.11 \pm 5.77(a)$ \\
\hline \multirow[t]{3}{*}{ SWC } & $\mathrm{Z} 1$ & $0.12 \pm 0.01$ (a) & $0.07 \pm 0.02(\mathrm{~b})$ & $0.13 \pm 0.03(\mathrm{a})$ & $0.02 \pm 0.01(\mathrm{a})$ & $0.013 \pm 0(a)$ & $0.11 \pm 0.03(\mathrm{a})$ & $0.12 \pm 0.01(\mathrm{a})$ \\
\hline & $\mathrm{Z} 2$ & $0.13 \pm 0.02$ (a) & $0.09 \pm 0.02(\mathrm{a})$ & $0.14 \pm 0.02$ (a) & $0.02 \pm 0.01(\mathrm{a})$ & $0.017 \pm 0(\mathrm{a})$ & $0.12 \pm 0.01(\mathrm{a})$ & $0.13 \pm 0.01(\mathrm{a})$ \\
\hline & $\mathrm{Z3}$ & $0.12 \pm 0.01$ (a) & $0.09 \pm 0(a)$ & $0.13 \pm 0.02(\mathrm{a})$ & $0.02 \pm 0.01$ (a) & $0.016 \pm 0$ (a) & $0.11 \pm 0(\mathrm{a})$ & $0.12 \pm 0.01(\mathrm{a})$ \\
\hline
\end{tabular}

Different letters indicate significant differences $(\mathrm{p}<0.05)$ between means of delimited zones.

T a b l e 2. Representativeness of the quartile based classification for the delimited zones ( $Z 1, Z 2$ and $Z 3$ ) of every survey and the delimited classes (C1, C2 and C3). Cells represent the number of locations of each zone included in each class, for every survey

\begin{tabular}{cccccccc}
\hline \multirow{2}{*}{ Classes } & \multicolumn{7}{c}{ Survey } \\
\cline { 2 - 7 } & 10 & 12 & 13 & 15 & 16 & 17 & 18 \\
\hline $\mathrm{C} 1$ & $9 / 10$ & $9 / 10$ & $9 / 10$ & $8 / 10$ & $8 / 10$ & $8 / 10$ & $10 / 10$ \\
$\mathrm{C} 2$ & $14 / 15$ & $10 / 15$ & $11 / 15$ & $7 / 15$ & $8 / 15$ & $12 / 15$ & $10 / 15$ \\
$\mathrm{C} 3$ & $15 / 15$ & $13 / 15$ & $15 / 15$ & $11 / 15$ & $11 / 15$ & $15 / 15$ & $14 / 15$ \\
\hline
\end{tabular}

significant differences between the zones for clay and stone content, while no significant differences were found for $\rho_{b}$. Clay content had significantly lower average values in $Z 1$ as compared to $\mathrm{Z} 2$ and $\mathrm{Z3}$ in five surveys, and significantly lower clay contents in $\mathrm{Z} 1$ as compared to $\mathrm{Z} 2$ in surveys 15 and 16 . Average stone content values were significantly higher in $\mathrm{Z1}$ as compared to $\mathrm{Z} 2$ in surveys 12 and 15 . Nevertheless, average $S W C$ s were only lower in $Z 1$ than in Z2 and Z3 in survey 12. Surveys 15 and 16 were characterised by low $S W C$ s, while survey 12 had intermediate to high $S W C$ s. Therefore, when the $S W C$ does not hamper the straightforward interpretation of clay and stone content, $E C a$ is a tool to spatially classify these soil properties. Intermediate $S W C$ s are required in this eroded and stony soil to distinguish significantly different zones.

Results from the PCA showed that the first $\mathrm{PC}$ accounted for $86 \%$ of the total variance of spatial soil $E C a$. Therefore, the first $\mathrm{PC}$ was considered as the time-stable dominant spatial pattern of $E C a$ (Fig. 3b). The first and third quartiles, -5.2 and 4.5 respectively, were used to group the 41 sampling locations in the following classes: $\mathrm{C} 1$, locations with $\mathrm{PC} 1<-5.2$; $\mathrm{C} 3$, locations with $\mathrm{PC} 1>4.5$; and $\mathrm{C} 2$, locations with $\mathrm{PC} 1$ outside the data range for $\mathrm{C} 1$ and $\mathrm{C} 2$.
Evaluation of the quartile based spatial classifications for the $7 E C a$ maps (Table 2) indicated that classifications of $Z 1$ and $Z 3$ obtained from those single surveys were close to the spatial classification based on the first PC at field averaged $S W C \mathrm{~s}>0.11 \mathrm{~kg} \mathrm{~kg}^{-1}$. Spatial classifications of Z2 differed from $\mathrm{C} 2$ for the 7 individual ECa maps, as compared to Z1 and Z2. Spatial classification (Z1, Z2 and Z3) of survey 10 showed the best overlap with spatial classification based on the first PC ( $\mathrm{C} 1, \mathrm{C} 2$ and $\mathrm{C} 3)$. The soil was surveyed in October, once the first rainfalls were recorded after the characteristic dry Mediterranean summer (Fig. 2). Overall, the percentage of locations included in $\mathrm{Z} 1$ for the corresponding $\mathrm{C} 1$ was $87 \%$, the percentage of $\mathrm{Z} 2$ in $\mathrm{C} 2$ was $69 \%$, and the percentage of $Z 3$ included in $\mathrm{C} 3$ was $81 \%$. Percentages of locations for $\mathrm{Z} 1$ and $\mathrm{Z} 3$ in $\mathrm{C} 2$, and for $\mathrm{Z} 2$ in $\mathrm{C} 1$ were all lower than $13 \%$. Although, the percentage of locations for Z3 included in $\mathrm{C} 2$ was $31 \%$, indicating that this area is more variable in time, probably as a result of the higher clay contents.

Soil properties were substantially different among the quartile base classification of the first PC $(\mathrm{C} 1, \mathrm{C} 2$ and C3). The ANOVA test indicated significant differences $(p<0.05)$ for clay and stone content, and no differences for 
$\rho_{b}$ among the classes (Table 1). Class $\mathrm{C} 2$ showed significantly higher clay contents $(19.33 \pm 2 \%)$, causing significantly higher $E \mathrm{Ca}$ values in this class as compared to $\mathrm{C} 1$ and $\mathrm{C} 3$. Stone content was significantly higher in $\mathrm{C} 1(10.75 \pm 6 \%)$, where the lowest $E C a$ values were found. Significant differences for $S W C$ among the classes were only detected for survey $16, \mathrm{C} 2$ showed significantly higher $S W C$ s $(0.018 \pm$ $0.004 \mathrm{~kg} \mathrm{~kg}^{-1}$ ). This may be, however, the result of a small magnitude of $S W C$ variation.

Based on the results from the averaged relationships between $S W C$ and $E C a$ (Fig. 4), an exponential model was fitted for each sampling location using the data from the nine different surveys. Descriptive statistics for the fitting parameters $a$ and $b$ showed averaged values of 3.8 and 14.2, respectively. Parameter $a$ doubled the $C V$ and showed half the range of parameter $b$. The ANOVA test indicated that parameter $a$ was significantly smaller in $\mathrm{C} 1$ as compared to $\mathrm{C} 2$ and $\mathrm{C} 3$. For parameter $b$ no significant differences were found between the classes. Therfore, parameter $a$ might be related to the soil properties that control the first PC pattern and classification, which is mainly the ECa. Parameter $a$ showed lower values in the northern part of the catchment, in the area with low clay and high stone contents. Although

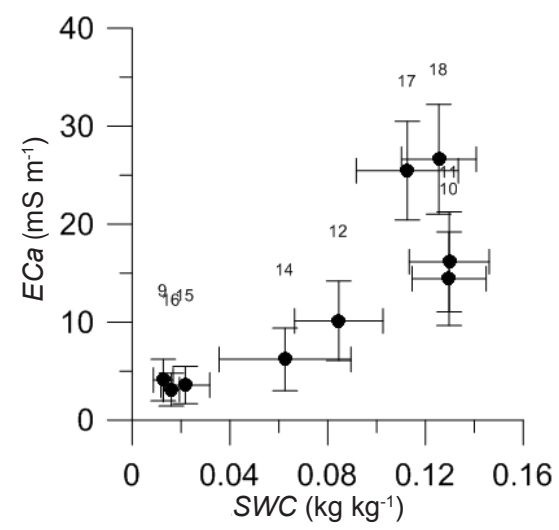

Fig. 4. Relationship between spatially averaged soil water content $\left(S W C, \mathrm{~kg} \mathrm{~kg}^{-1}\right)$ and apparent electrical conductivity $\left(E C a, \mathrm{mS} \mathrm{m}^{-1}\right)$. Error bars represent standard deviations.

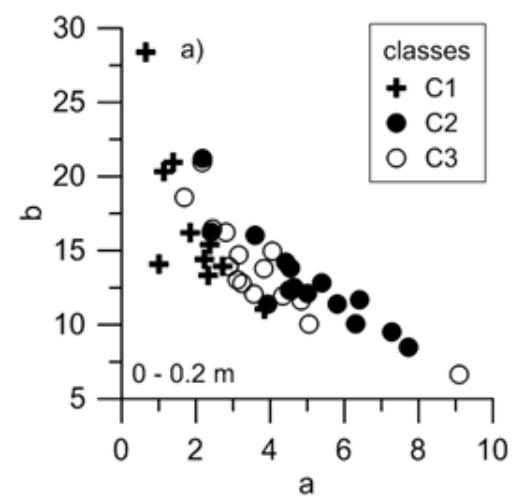

the explored soil volumes for the $E C a$ and topsoil measurements differed by several orders of magnitude and no strong correlations were expected, the relationship between the $E C a$ and $S W C$ data for each sampling location showed a maximum RMSE of 11.5 and a range of 0.45-0.94 for $\mathrm{R}^{2}$. These results showed clearly that these topsoil properties influence the $S W C$ and $E C a$ relationships; as significant differences between the classes were found for the studied soil properties and for the adjusted parameters.

The relationship between the first PC and parameter $a$ was further analysed to interpret the link between the first $\mathrm{PC}$ and the exponential $S W C-E C a$ relationships (Fig. 5). As expected, an inverse relationship was obtained between parameters $a$ and $b$. An inverse linear relationship was found between $a$ and $\mathrm{PC} 1\left(\mathrm{R}^{2}=0.62\right)$, indicating that the lower PC1 was, the smaller the $E C a$ value when the $S W C$ reached its maximum. The particular established relationship could be used to interpret $S W C$ distributions through ECa measurements.

\section{DISCUSSION}

The ECa exhibited a strong temporal stability in this work. A single first PC was able to explain $86 \%$ of the spatial variability. This percentage of explained variability was larger than analogous values obtained in applications of PCA to soil water contents in previous studies. Korres et al. (2010) reported that their analysis resulted in one significant spatial structure (first PC) which explained $57.5 \%$ of the spatial variability connected to soil properties and topography. Similarly, Perry and Niemann (2007) found that the first PC explained about $55 \%$ of the spatial variance in soil water contents. One possible reason for this is that the variability of $E C a$ during dry spells is mostly controlled by clay content which is obviously a spatially stable soil property. The high percentage of explained variability makes the first PC a promising variable to define management zones and predict spatial distribution of soil and crop properties, such as soil water content or yield. Other metrics of temporal stability also have high values. In particular, computation of correlations between $E C a$ measured at the

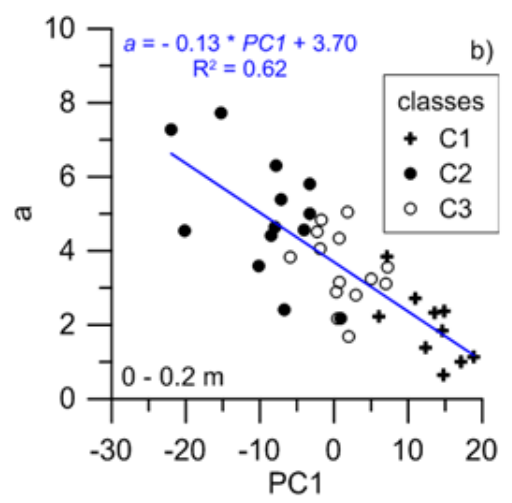

Fig. 5. a) Relationship between parameters $a$ and $b$, and b) relationship between parameter $a$ and first principal component (PC1) for classes $\mathrm{C} 1, \mathrm{C} 2$ and $\mathrm{C} 3$. The result of a joint linear regression for the three classes is shown. 
same location in two different surveys, as suggested by de Caires et al. (2015) and Serrano et al. (2013), provided values of the correlation coefficient (R) from 0.75 to 0.97 in this work (data not shown).

Spatial scales of $E C a$ and $S W C$ measurements differed by orders of magnitude. Besides, the DOE of the $E C a$ measurements was larger than the soil depth for which water content was measured. Nevertheless, strong correlations were observed between $E C a$ and $S W C$. One possible reason may be the correlative relationships between $E C a$ measured with different coil configurations. For example, $\mathrm{R}$ between the different $\mathrm{ECa}$ signals and the selected one ( $1.5 \mathrm{~m}$ DOE) ranged from 0.75 to 0.95 , indicating strong and significant $(\mathrm{p}<0.05)$ relationships for all survey dates (data not shown).

Relationships between averaged $E C a$ and $S W C$ values followed the exponential model; this type of relationship was observed in earlier works (Celano et al., 2011; McCutcheon et al., 2006; Mishra et al., 2014). This exponential relationship held at $S W C$ s below $0.11 \mathrm{~kg} \mathrm{~kg}^{-1}$, but was not applicable at higher water contents, possibly because of the presence of complex vertical distributions of soil water content in the wet soil. The coefficients in the exponential relationship between $E C a$ and water content at each sampling location varied with the first $\mathrm{PC}$ value. These findings indicate that no unique relationship existed between $E C a$ and $S W C$ for the entire study field, as noted by Islam et al. (2011), Pedrera-Parrilla et al. (2014), and Robinson et al. (2009).

The spatial pattern of $E C a$, represented by the first PC, was significantly related with soil properties in this work. In previous studies, Jawson et al. (2007) demonstrated a relationship between soil texture and the spatial and temporal variation in large-scale soil moisture patterns using PCA. Qiu et al. (2014) analysed the soil moisture variability of various spatial scales based on PCs, and connected the spatial patterns to topography and soil texture at the studied spatial scales. Our study indicated that the spatial pattern of $E C a$ was related to clay, stone and soil water content. The lowest clay contents and $S W C$ s, as well as the highest stone content, were located in the area that corresponded to $\mathrm{C} 1$. This particular spatial distribution of soil properties led to the lowest $E C a$ values in this area.

Three distinct zones were established in this study. Literature shows that three is the most likely selected number of classes to represent soil spatial variability (Hedley et al., 2009; Jiang et al., 2012; Li et al., 2013), while other authors defined only two zones (Bonfante et al., 2015, De Caires et al., 2015).

\section{CONCLUSIONS}

Temporal stability of electrical conductivity was determined using principal component analysis based on seven electrical conductivity surveys. The first principal compo- nent, which represented the time-stable dominant spatial electrical conductivity pattern in a sandy soil, was used to delimit three areas $(\mathrm{C} 1, \mathrm{C} 2$ and $\mathrm{C} 3)$ with similar soil conditions.

1. Clay and stone contents were found to be spatially and significantly different among the classes, while soil water content was only spatially different for surveys at intermediate soil water contents. Clay content, soil water content and electrical conductivity showed the lowest values in $\mathrm{C} 1$, while stone content showed the highest values. No spatial differences were found for bulk density. Overall results indicated strong interactions among the analysed soil properties in this eroded and heterogeneous olive grove.

2. Relationships between averaged soil water content and electrical conductivity values were also explored. A clear exponential relationship between spatially averaged soil water content and electrical conductivity was found, although the relationship became indeterminate for water contents above $0.11 \mathrm{~kg} \mathrm{~kg}^{-1}$. The exponential curve also modelled the above mentioned relationship at each sampling location.

3. The fitted parameter a showed a strong inverse relationship with the first principal component. Therefore, the fitted inverse relationship between parameter a and the first principal component can be used as a simple model to interpret $S W C$ distribution through the time-stable dominant spatial electrical conductivity pattern.

4. These findings show that more than a single valid relationship is needed to fully characterise the entire field, and that physical topsoil properties influence the SWC and ECa relationships.

Conflict of interest: The Authors do not declare conflict of interest.

\section{REFERENCES}

Blake G.R. and Hartge K.H., 1986. Bulk density In: Methods of Soil Analysis: Part 1. Physical and mineralogical methods (Ed. A. Klute). Agronomy SSSA Book Ser. 9. SSSA, Madison, WI, USA.

Bonfante A., Agrillo A., Albrizio R., Basile A., Buonomo R., de Mascellis R., Gambuti A., Giorio P., Guida G., Langella G., Manna P., Minieri L., Moio L., Siani T., and Terribile F., 2015. Functional homogeneous zones (fHZs) in viticultural zoning procedure: an Italian case study on Aglianico vine. Soil, 1, 427-441.

Brevik E.C., Calzolari C., Miller B.A., Pereira P., Kabala C., Baumgarten A., and Jordán A., 2016. Soil mapping, classification, and modeling: history and future directions. Geoderma, 264, 256-274, doi:10.1016/j

Brevik E.C. and Fenton T.E., 2004. The effect of changes in bulk density on soil electrical conductivity as measured with the Geonics EM-38. Soil Surv. Horiz., 45(3), 73-110.

Callegary J.B., Ferré T.P.A., and Groom R.W., 2007. Vertical spatial sensitivity and exploration depth of low-inductionnumber electromagnetic-induction instruments. Vadose Zone J., 6, 58-167. 
Celano G., Palese A.M., Ciucci A., Martorella E., Vignozzi N., and Xiloyannis C., 2011. Evaluation of soil water content in tilled and cover-cropped olive orchards by the geoelectrical technique. Geoderma, 163, 163-170.

De Caires S.A., Wuddivira M.N., and Bekele I., 2015. Spatial analysis for management zone delineation in a humid tropic cocoa plantation. Precis Agric., 16, 129-147.

Doolittle J.A., and Brevik E.C., 2014. The use of electromagnetic induction techniques in soils studies. Geoderma, 223-225, 33-45.

Dualem Inc., 2007. DUALEM-21S user's manual. Dualem Inc., Milton, Canada.

Espejo A., Giráldez J.V., Vanderlinden K., Taguas E.V., and Pedrera A., 2014. A method for estimating soil water diffusivity from moisture profiles and its applications across an experimental catchment. J. Hydrol., 516, 161-168.

Farahani H.J. and Buchleiter G.W., 2004. Temporal stability of soil electrical conductivity in irrigated sandy fields in Colorado. Trans. ASAE, 47(1), 79-90.

García del Barrio I., Malvárez L., and González J.I., 1971. Mapas provinciales de suelos (Provincial soil maps). Cádiz. Ministerio de Agricultura. Madrid, Spain.

Gee G.W. and Or D., 2002. Particle-size analysis. In: Methods of Soil Analysis. Part 4. Physical Methods (Eds J.H. Dane and G.C. Topp). SSSA Book Ser. 5. SSSA, Madison, WI, USA.

Goovaerts P., 1997. Geostatistics for natural resources evaluation. Oxford UniversityPress, Oxford, UK.

Gómez J.A., Guzmán M.G., Giráldez J.V., and Fereres E., 2009. The influence of cover crops and tillage on water and sediment yield and on nutrient, and organic matter losses in an olive orchard on a sandy loam soil. Soil Till. Res., 106, 137-144.

Grossman R.B. and Reinsch T.G., 2002. Bulk density and linear extensibility. In: Methods of Soil Analysis. Part 4. Physical Methods (Eds J.H. Dane and G.C. Topp). SSSA Book Ser. 5. SSSA, Madison, WI, USA.

Hedley C.B. and Yule I.J., 2009. A method for spatial prediction of daily soil water status for precise irrigation scheduling. Agr. Water Manag., 96, 1737-1745.

Heilig J., Kempenich J., Doolittle J., Brevik E.C., and UImer M., 2011. Evaluation of electromagnetic induction to characterize and map sodium-affected soils in the northern Great Plains. Soil Surv. Horiz., 52, 77-88.

Ibañez J.J., Pérez-Gómez R., Oyonarte C., and Brevik E.C., 2015. Are there arid land soilscapes in southwestern Europe? Land Degrad. Develop., doi:10.1002/ldr.2451.

Islam M.M., Saey T., Meerschman E., De Smedt P., Meeuws F., Van De Vijver E., and Van Meirvenne M., 2011. Delineating water management zones in a paddy rice field using a Floating Soil Sensing System. Agr. Water Manag., 102, 8-12.

Jawson S.D. and Niemann J.D., 2007. Spatial patterns from EOF analysis of soil moisture at a large scale and their dependence on soil, land-use, and topographic properties. Adv. Water Resour., 30, 366-381.

Jiang H.L., Liu G.S., Liu S.D., Li E.H., Wang R., Yang Y.F., and Hu H.C., 2012. Delineation of site-specific management zones based on soil properties for a hillside field in central China. Archiv. Agron. Soil Sci., 58, 1075-1090, doi: 10.1080/03650340.2011.570337.
Keesstra S., Pereira P., Novara A., Brevik E.C., Azorin-Molina C., Parras-Alcántara L., Jordán A., and Cerdà A., 2016. Effects of soil management techniques on soil water erosion in apricot orchards. Sci. Total Environ., 551-552, 357-366.

Korres W., Koyama C.N., Fiener P., and Schneider K., 2010. Analysis of surface soil moisture patterns in agricultural landscapes using empirical orthogonal functions. Hydrol. Earth Syst. Sci., 14, 751-764.

Li Y., Shi Z., and Li F., 2007. Delineation of site-specific management zones based on temporal and spatial variability of soil electrical conductivity. Pedosphere, 17(2), 156-164.

Li Y., Shi Z., Wu H.X., Li F., and Li H.Y., 2013. Definition of management zones for enhancing cultivated land conservation using combined spatial data. Environ. Manag., 52, 92-806.

Malinowski E.R., 1991. Factor Analysis in Chemistry. John Wiley and Sons Press, New York, USA.

Martinez G., Vanderlinden K., Ordoñez R., and Muriel J.L., 2009. Can apparent electrical conductivity improve the spatial characterization of soil organic carbon? Vadose Zone J., 8(3), 586-593.

Martinez-García G., Vanderlinden K., Pachepsky Y., GiráldezCervera J.V., and Espejo-Pérez A.J., 2012. Estimating topsoil water content of clay soils with data from time-lapse electrical conductivity surveys. Soil Sci., 177(6), 369-376.

McCutcheon M.C., Faharani H.J., Stednick J.D., Buchleiter G.W., and Green T.R., 2006. Effect of soil water on apparent soil electrical conductivity and texture relationships in a dryland field. Biosyst. Eng., 94(1), 19-32.

McNeill J.D., 1980. Electromagnetic terrain conductivity measurement at low induction numbers. Technical Note TN-6. Geonics Limited. Missisauga, Ontario, Canada.

Mishra R.K. and Padhi J., 2014. Assesing field-scale soil water distribution with electromagnetic induction method. J. Hydrol., 516, 200-209.

Núñez-Maderal E., 2008. Calculadora Geodésica edición especial para la Península Ibérica (Geodesic calculator special edition for the Iberian peninsula), Cartesia.org, Spain. http://www.cartesia.org/download.php?op=viewdownload details \&lid $=172 \&$ ttitle $=$ Calculadora_UTM-Geogr $\%$ E1ficas_Espa\%F1a

Pedrera-Parrilla A., Martínez G., Espejo-Pérez A.J., Gómez J.A., Giráldez J.V., and Vanderlinden K., 2014. Mapping impaired olive tree development using electromagnetic induction surveys. Plant Soil., 384, 381-400.

Pedrera-Parrilla A., Van De Vijver E., Van Meirvenne M., Espejo Pérez A.J., Giráldez J.V., and Vanderlinden K., 2016. Apparent electrical conductivity measurements in an olive orchard under wet and dry soil conditions: significance for clay and soil water content mapping. Precis Agric., doi:10.1007/s11119-016-9435-Z

Peralta N.R., Costa J.L., Balzarini M., and Angelini H., 2013. Delineation of management zones with measurements of soil apparent electrical conductivity in the southeastern pampas. Can. J. Soil Sci., 93(2), 205-218.

Perry M.A. and Niemann J.D., 2007. Analysis and estimation of soil moisture at the catchment scale using EOFs. J. Hydrol., $334,388-404$. 
Qiu J., Mo X., Liu S., and Lin Z., 2014. Exploring spatiotemporal patterns and physical controls of soil moisture at various spatial scales. Theor. Appl. Clim., 118, 159-171.

Robinson D.A., Lebron I., Kocar B., Phan K., Sampson M., Crook N., and Fendorf S., 2009. Time-lapse geophysical imaging of soil moisture dynamics in tropical deltaic soils: An aid to interpreting hydrological and geochemical processes. Water Resour. Res., doi:10.1029/2008WR006984.

Saey T., Simpson D., Vitharana U.W.A., Vermeersch H., Vermang J., and van Meirvenne M., 2008. Reconstructing the paleotopography beneath the loess cover with the aid of an electromagnetic induction sensor. Catena, 74, 58-64.

Serrano J.M., Shahidian S., and Da Silva J.R., 2013. Apparent electrical conductivity in dry versus wet soil conditions in a shallow soil. Precision Agric., 14, 99-114.

Sheets K.R. and Hendrickx J.M.H., 1995. Noninvasive soil water content measurement using electromagnetic induction. Water Resour. Res., 31(10), 2401-2409.

Simpson D., 2009. Geoarchaeological prospection with multicoil electromagnetic induction sensors. Ph.D. thesis, Dept. Soil Management, Faculty of Bioscience Engineering, Ghent University.

Soil Survey Staff, 1999. Soil taxonomy: A basic system of soil classification for making and interpreting soil surveys. USDA-NRCS Agrc. Hdbk. 436. US Gov. Print. Office, Washington, DC, USA.
Sudduth K.A., Kitchen N.R., Bollero G.A., Bullock D.G., and Wiebold W.J., 2003. Comparison of electromagnetic induction and direct sensing of soil electrical conductivity. Agron. J., 95, 472-482.

Symeonakis E., Karathanasis N., Koukoulas S., and Panagopoulos G., 2014. Monitoring sensitivity to land degradation and desertification with the environmentally sensitive area index: the case of Lesvos Island. Land Degrad. Develop., doi: 10.1002/ldr.2285.

Taguas E.V. and Gómez J.A., 2015. Vulnerability of olive orchards under the current CAP (CommonAgricultural Policy) regulations on soil erosion: a study case in Southern Spain. Land Use Pol., 42, 683-694.

Vanderlinden K., Vereecken H., Hardelauf H., Herbst M., Martinez G., Cosh M.H., and Pachepsky Y.A., 2012. Temporal stability of soil water contents: A review of data and analyses. Vadose Zone J., doi:10.2136/vzj2011.0178.

Vanwalleghem T., Infante-Amate J., González de Molina M., Soto-Fernández D., and Gómez J.A., 2011. Quantifying the effect of historical soil management on soil erosion rates in Mediterranean olive orchards. Agr. Ecosyst. Environ., 142, 341-351.

Vaudour E., Costantini E., Jones G.V., and Mocali S., 2015. An overview of the recent approaches to terroir functional modelling, footprinting and zoning. Soil, 1, 287-312.

Whelan B.M., McBratney A.B., and Minasny B., 2002. Vesper 1.5 - spatial prediction software for precision agriculture, In: Precision Agriculture, Proc. 6th Int. Conf. Precision Agriculture (Eds P.C. Robert, R.H. Rust and W.E. Larson). ASA/CSSA/SSSA, Madison, WI, USA. 